\title{
Cem anos de estranhamento
}

////////////////// Irene Machado ${ }^{1}$

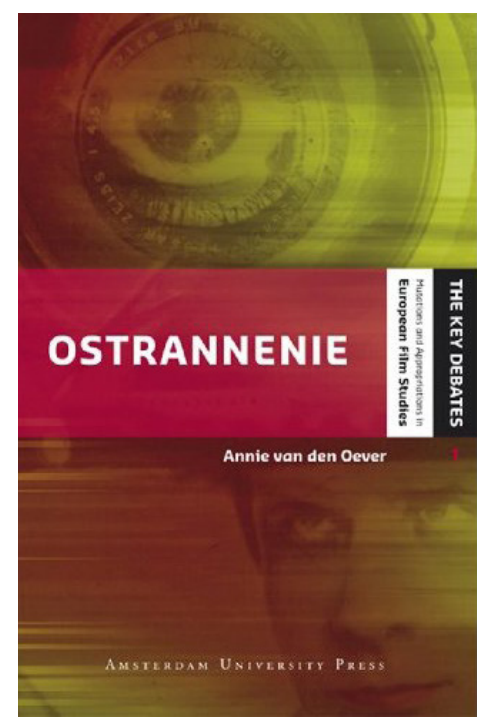

\section{Resenha}

OEVER, A. van den (Ed.).

Ostrannenie. on "strangeness"

and the moving image.

The history, reception, and

relevance of a concept.

Amsterdam: Amsterdam

University Press, 2010.

1. Professora livre-docente no Programa de Pós-Graduação em

Comunicação e no Departamento de Comunicações e Artes da Escola de Comunicações e Artes da Universidade de São Paulo.

E-mail: irenemac@uol.com.br 


\section{Resumo}

Como o conceito de estranhamento emergiu no campo da linguagem poética e se tornou manifestação essencial da experiência estética? Como os procedimentos técnico-cinemáticos transformaram a percepção do mundo visível? De respostas a essas questões nasceram os artigos reunidos nesse livro sobre o papel do conceito de estranhamento não apenas na Rússia dos anos 20 como também no cinema e nos meios de comunicação.

\section{Palavras-chave}

Cinema, estranhamento, ostranenie, Chklóvski.

\section{Abstract}

How did the concept of ostranenie (strangeness) emerge in poetic language and become the manifestation of aesthetic experience? How did the technical cinematic devices transform the perception of the visual world? From the answers to these questions the articles of this book about the role of the concept of ostranenie were born. These cover not only the artistic movement in Russia during the 20' but also those of cinema and media.

Keywords

Cinema, strangeness, ostranenie, Chklóvski. 


\section{Um manifesto feito para durar}

No calor de seus 20 anos, com a licença de um provocativo estudante da Universidade de São Petersburgo, Victor Chklóvski abriu fogo contra as práticas dos estudos literários de sua época. Seu objetivo era desbancar a poética consagrada pelas impressões e pelo continuísmo. Num texto-manifesto datado de 1913, negou a poesia baseada em reconhecimentos de metáforas desgastadas, empregadas à exaustão como garantia de uma compreensão facilitada e previsível.

Diante das provocativas experiências da poesia cubofuturista, da arte construtivista e do próprio simbolismo russo, o jovem conclamava os teóricos a adotarem o partido da "desautomatização" dos sentidos. Pregava a urgência em valorizar as experiências de percepção da forma baseada na singularidade de novos procedimentos poéticos e no efeito de estranhamento. Com essa tríade, arte (iskusstvo), procedimento (priom) e estranhamento (ostranenie), Chklóvski lançou seu manifesto. 


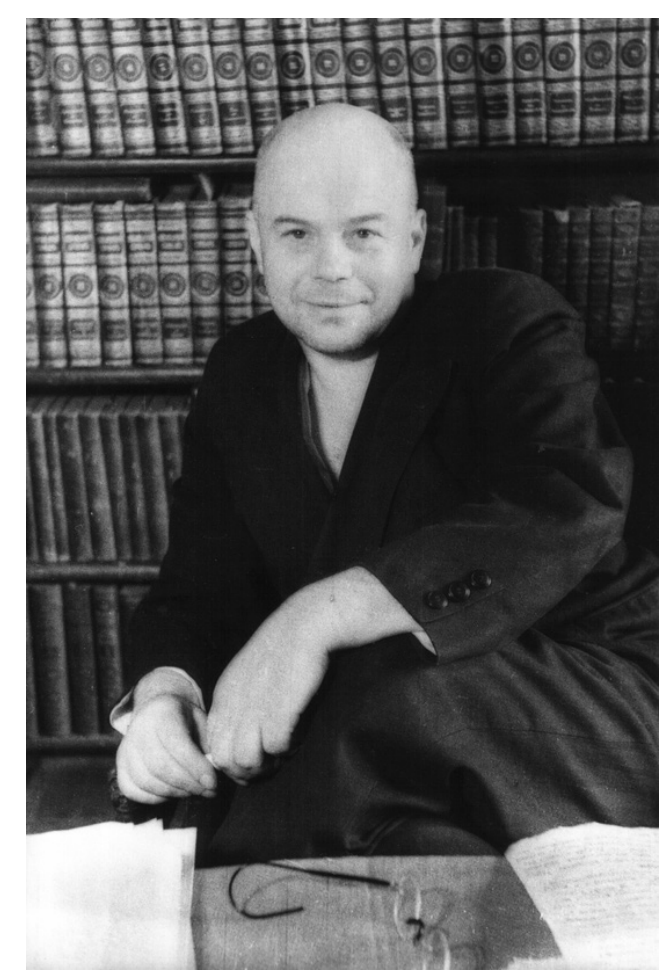

Ostranenie era a palavra-chave que assegurava a poética fundada na percepção estética livre de automatismos. Formulada em seu texto-manifesto "A arte como procedimento" (Iskusstvo kak priom), de 1913, tornou-se bandeira das ideias construtivistas, da poesia cubofuturista e do formalismo russo que convulsionaram o cenário crítico-criativo da Rússia dos anos 20. Alvo de ataques conservadores, o grupo, que, juntamente com Chklóvski, propagou o movimento formal, manteve-se atento aos experimentos que incorporavam ferramentas de produção gráfica e óptica, em nome da percepção inusitada de formas estéticas.

Hoje, passados cem anos, será que há algum motivo para comemoração? Sob o fogo cruzado dos ataques contra o princípio formal, quase nada mudou. O princípio formal mantém o estigma da falta de engajamento. Contudo, examinando com atenção o desdobramento das ideias artísticas, é possível ver os frutos. Ainda que condenado, o princípio do estranhamento foi concebido para durar para além do que Chklóvski havia formulado. 
Uma prova inquestionável nesse sentido encontra-se desenvolvida no livro intitulado Ostrannenie. Sobre o estranhamento e a imagem em movimento. História, recepção e relevância de um conceito, lançado em 2010 por iniciativa de Annie van den Oever, da Universidade de Amsterdam. Nele, a grande desenvoltura do conceito de estranhamento no campo das ideias artísticas e políticas foi examinada pela nova geração de teóricos cujas experiências estéticas se sustentam pelas imagens fílmicas e fotográficas, bem como pelas linguagens dos meios de comunicação.

Flagrando um daqueles reveses da história, o livro afirma indiretamente como a crescente presença dos meios de comunicação contribuiu para reverter a rejeição ao princípio formalista de percepção estética da forma. Pouco importa se seus contemporâneos não entenderam o trabalho conjugado que teóricos, poetas, artistas gráficos, fotógrafos, cineastas e designers realizaram ao experimentarem a percepção estética da forma e o efeito de estranhamento com os novos instrumentos ópticos e gráficos. Os meios de comunicação avançaram nos seus desígnios, e o novo vocabulário das artes ocupou o lugar que a história lhe reservava. Não apenas o princípio da linguagem poética entrou para a composição de textos culturais como a própria noção de estranhamento tornou-se requisito sem o qual a comunicação não cumpriria seu objetivo.

\section{Frutos do princípio poético da forma}

Muito embora seja anunciado como uma coletânea de uma nova série lançada pela Amsterdam University Press como revisão dos conceitos estético-filosóficos nos estudos de cinema (film studies), o livro Ostrannenie merece atenção por dimensionar o legado que as ideias formalistas e construtivistas deixaram para a consolidação do campo da análise fílmica no contexto da nova recepção cultural mediada pelos meios, como percebeu e formulou teoricamente Yuri Tsivian. Em cada um dos 13 artigos do livro, são recuperados não apenas os diferentes eixos conceituais como também suas implicações em termos da nova experiência estética da cultura audiovisual, que os formalistas e os construtivistas ajudaram a semear. 
Operando prioritariamente com informação cinemática, em todos os sentidos de sua expressão, os estudos reunidos no livro mostram como a poética deslocou a supremacia do código verbal. Sem negar a força construtiva da palavra, a poética formalista acompanhou os movimentos e os desdobramentos que os signos históricos de outros códigos culturais foram introduzindo no cenário das artes, sobretudo ao incorporar instrumentos tecnológicos e adentrar no campo industrial. A arte ganha uma nova gestualidade, a cultura, novas linguagens, os artistas, novos códigos, como a tipografia e as câmeras foto e cinematográficas.

"Palavra imagem movimento" é a conjugação singular que emerge como signo de uma nova agremiação. Não se trata de apenas manipular tipos gráficos, lentes e câmeras, mas, sim, de explorar possibilidades para além delas. Quer dizer, criar ambientes em que os signos são deslocados de seu habitat natural - caso da palavra impressa que se levanta para ocupar muros e cartazes.

FIGURA 2 - Cartaz para o filme A aspereza (1927).

Dir. de A. Room, com roteiro de $\mathrm{V}$. Chklóvski

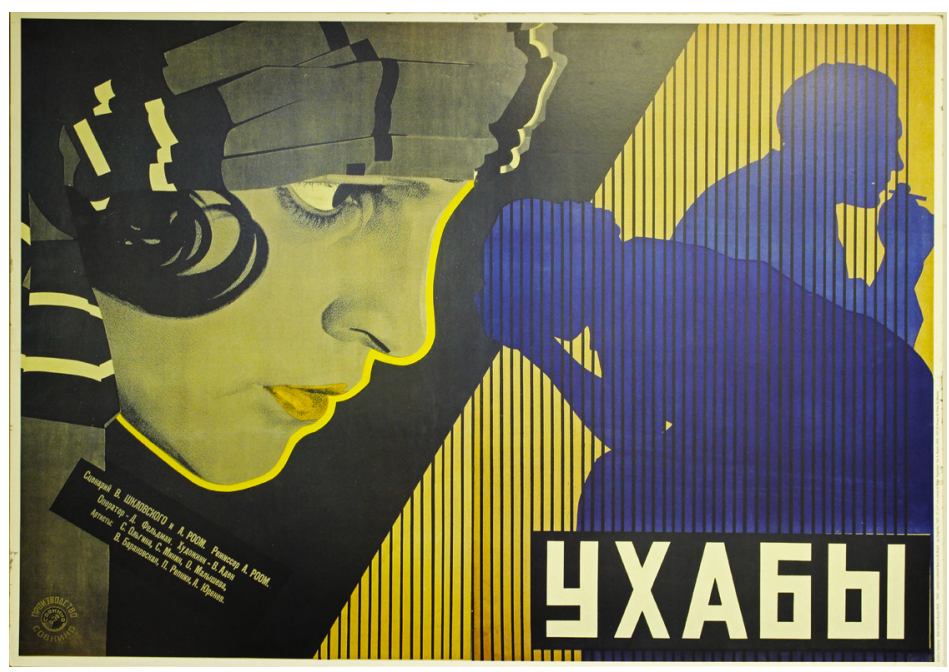

Assim nasciam os procedimentos que incidiam diretamente sobre a percepção. Uma simples intervenção em linhas (do verso, da pintura, das tomadas, da vibração sonora), em luzes, ângulos, texturas e em telas era o suficiente para provocar estranhamento. Com isso, a poesia ganha força expressiva na exploração conjunta de meios impressos, sonoros e cinéticos traduzidos em experiência estética. Poesia, fotografia, cartaz e imagem em movimento são 
apenas algumas das formas que, em interação, geravam novos procedimentos. Muitas dessas práticas criaram um habitat para o exercício sensorial de formas não cogitadas antes do século 20.

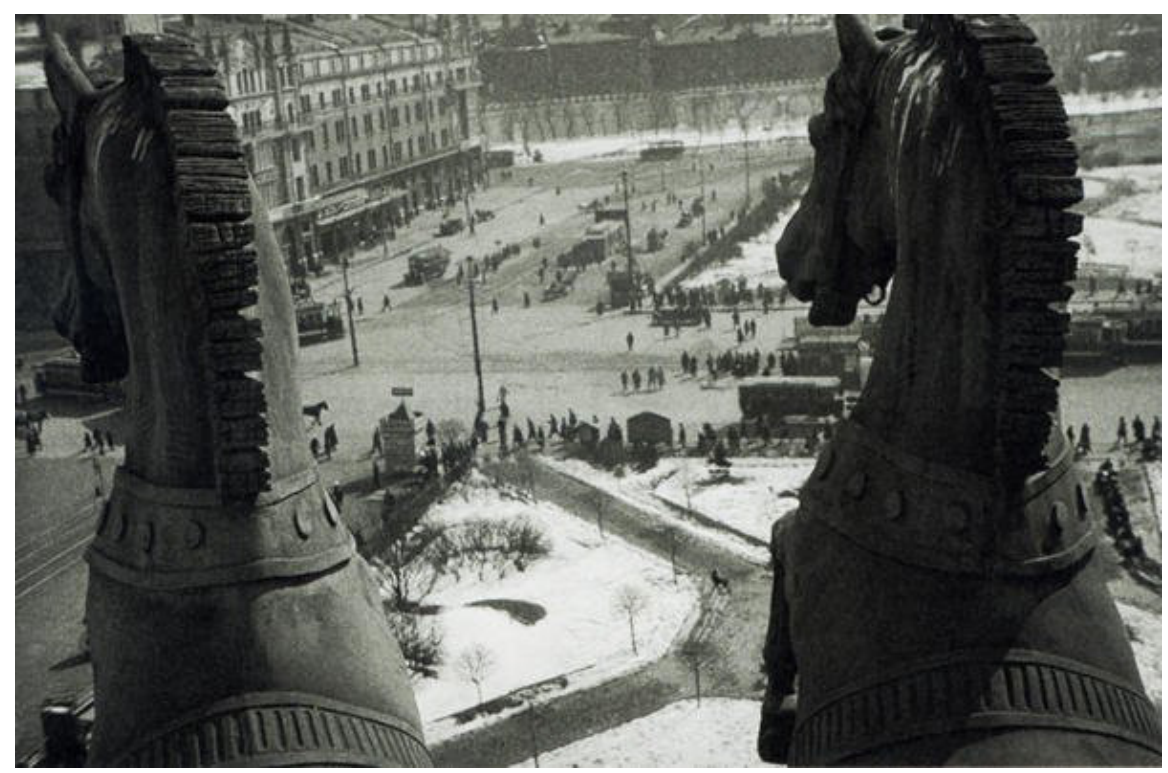

FIGURA 3 - Fotografia Quadriga of Apollo on the front of the Bolshoi Theatre, de Alexander Ródtchenko
E esse foi um legado que novas gerações de artistas e pesquisadores souberam explorar. É o que se acompanha no conjunto propositivo das quatro seções do livro.

\section{Um novo exercício de metalinguagem e recepção crítica}

É extremamente significativo que as primeiras páginas já tenham introduzido a noção de "gesto revolucionário" que Liév Tolstoi legou à geração dos anos 10-20 do século passado. Com base nessa formulação, Yuri Tsivian (p. 21-32) reconstrói o campo das ideias em que o gesto, anterior à palavra, define o "fazer artístico engajado no processo criativo" (p. 22). Nesse sentido, a fotografia de A. Ródtchenko e o cinema de D. Viértov e S. Eisenstein são os exemplos que Tsivian examina em sua análise. A nova recepção cultural parte da reelaboração desse cenário, em que os gestos são traduzidos com a mediação dos instrumentos. O legado formalista foi, assim, traduzido em termos de uma recepção crítica, revigorando o trabalho da metalinguagem, que passa a ser observada nos desdobramentos mais recentes dos estudos de mídia. 
Seguindo as formulações de Tsivian, A. van den Oever discute como os experimentos de gestos conjugados de incitação e atração; som e movimento; palavra e imagem fazem do corpo e da tecnologia parceiros do gesto revolucionário de nosso tempo, o que não deixa de ser um evento de estranhamento. Enquanto Tsivian acompanhou o desdobramento rumo à construção da recepção crítica, Van der Oever (p. 33-58) situou o cinema de atrações no contexto dos procedimentos construtivistas e do fortalecimento do "cinema-experiência", sobretudo a experiência de ir ao cinema, tal como o pensamento já clássico (de Máximo Gorki a Tom Gunning) soube dimensionar.

Trata-se de valorizar um modo de recepção cultural que não era uma mera reação ao filme nos moldes do que a experiência literária provocava. Experimentar a forma no cinema implicava mergulhar em um espaço de envolvimento que estava longe de ser apenas a visão de espectador. A arte futurista foi aqui revisitada em todo o envolvimento de experiência compartilhada que Van den Oever examina na "Introdução" (p. 11-18) e em seu artigo (p. 33-58).

Oscilando entre a retomada do campo conceitual e sua projeção na consolidação da analítica do cinema e da história da mídia, Frank Kessler (p. 61-79) sistematiza a repercussão no campo da narrativa. Nesse sentido, empreende uma análise comparativa nos estudos de Tom Gunning, David Bordwell e Kristin Thompson. Cada um, a seu modo, empreendeu análises da narrativa cinemática a partir da poética histórica constituída sobretudo a partir do campo conceitual do estranhamento.

Em vários de seus artigos, o livro registra a necessidade de revisão de mal-entendidos, como demonstram os textos da segunda parte. Entre eles, aquele que se manifesta como o mais urgente é a formulação que opõe estranhamento ao conceito de distanciamento de Bertold Brecht com o claro propósito de apontar a fragilidade do primeiro. Ian Christie assume a tarefa de rever tal mixórdia e começa por rever a genealogia dos conceitos - ostranenie (efeito de estranhamento) e verfremdungseffekt (efeito de alienação) em seu artigo (p. 81-109). Ainda que se tenha imposto ao conceito de Chklóvski uma carga negativa, na língua inglesa, o emprego não se confirmou, sobretudo no contexto do marxismo sobre alienação. 
Christie se orienta pelo quadro do debate que emergiu quando da tradução, para a língua inglesa, dos artigos de Brecht sobre o teatro épico. Nele, são lançadas novas luzes sobre as formulações formalistas, e o conceito de ostranenie passa por um novo processo de avaliação e discussão. Para isso, foi decisivo o papel da revista Screen, que, em seu editorial "Brecht e o cinema revolucionário", no verão de 1974, tratou do efeito do distanciamento no cinema como potencialidade dramática. O conceito brechtiano é focalizado não apenas no seu efeito antidramático, uma vez que a alienação isola a audiência de um envolvimento com o evento em foco, mas também no estímulo à consciência. É essa linha de entendimento que orienta a compreensão do cinema reflexivo e do distanciamento, tal como foram praticados por Jean-Luc Godard nos anos 60, sobretudo quando do surgimento do grupo Dziga Vertov, capitaneado por Godard, e do Berwick Street Collective associado a Chris Marker, na Inglaterra. Pelo menos sob essas práticas, os equívocos conceituais e epistemológicos parecem superados.

Se a noção de estranhamento se consagrou nos estudos de cinema como um princípio heurístico, Christian Metz cometeu um grande equívoco. Em seu artigo, Emile Poppe (p. 111-115) deixa claro que, apesar da omissão de Metz, sua pesquisa semiótica se constitui num legado direto do estranhamento.

Considerando que o núcleo duro da noção de estranhamento é a percepção, na terceira parte, o tema é examinado no contexto dos estudos de cognição e evolução. Reservou-se a parte final para conversações com os cineastas Laura Mulvey e András D. Kovács, no sentido de redimensionar o conceito em realizações contemporâneas - por exemplo, a noção de filme como texto.

Na conversa com Mulvey (p. 185-203), se envereda não apenas pela discussão do estranhamento no campo das vanguardas mas também pelo modo como a percepção estética da forma abre-se em direção à psicanálise, o que Mulvey trabalha em seu livro Death $24 \mathrm{x}$ a second: stillness and the moving image (2006), em que a própria natureza do cinema é posta em discussão. 


\section{Considerações finais}

Na própria organização dos artigos, se revela uma estratégia de quem se formou pelo viés dos tempos em que crítica de cinema não é lição que se aprende nos livros. A geração dos autores que colaboraram para a composição do livro levou adiante o exercício da produção teórica a partir da criação e da produção artística. Com isso, metalinguagem é um forte aliado da recepção crítica - que, na prática, marcaram o papel que as revistas de cinema tiveram como espaço de formação teórico-analítica.

Um pouco dessa história e desse papel vai sendo recuperado em vários dos artigos. Ecoa pelas páginas do livro o diálogo formador que os estudiosos da nova geração entabularam não apenas com os filmes mas sobretudo com os artigos de Poética Kino, Cahiers do Cinéma, Screen. Graças a esses periódicos, artigos fundamentais da vanguarda russa vieram a público e ampliaram o debate em outros espaços do Ocidente. Pelas revistas de análise de filmes, o cinema-experiência mantém-se como exercício vivo de conhecimento estético.

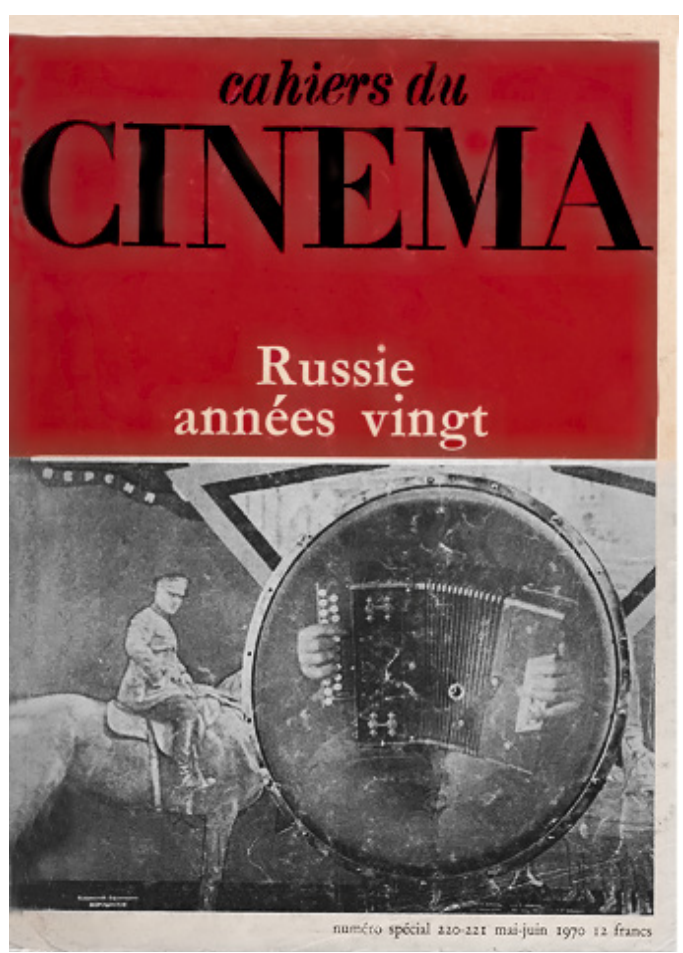


Esse é o maior tributo que o cinema-experiência poderia receber da parte de quem aprendeu a ler a produção audiovisual pelas lentes e luzes de formas elétricas. Ainda que a rejeição seja fato consumado, as ideias de V. Chklóvski não descansam em paz e ressoam nos exercícios estéticos da cena audiovisual contemporânea, ameaçando a consagração do automatismo, que continua rondando por todos os lados.

Talvez a melhor forma de celebração de pensamentos e teorias seja aquela que, em vez de apenas rememorar a fortaleza de suas raízes, seja capaz de apreender a qualidade de seus frutos. Penso que essa é a melhor forma de saudar os cem anos do estranhamento. 


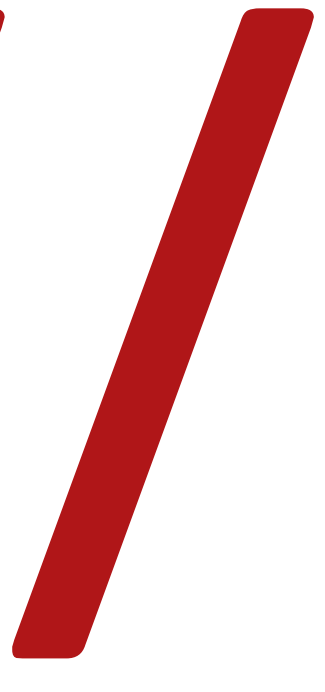

\section{Significação}

Revista de Cultura Audiovisual

julho-dezembro 2012
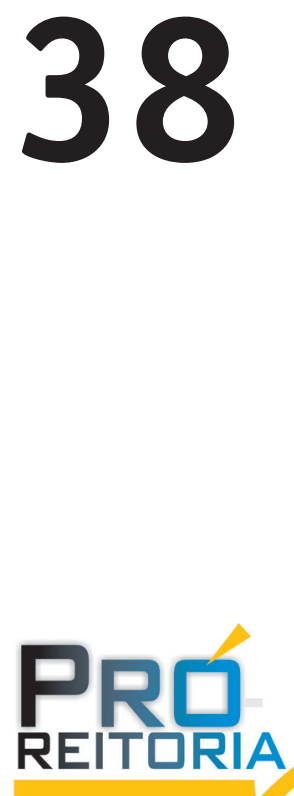

Pós-GraduaçãoTSP
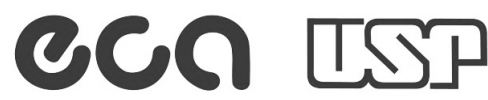

ESCOLA DE COMUNIČAÇÕES E ARTES UNIVERSIDADE DE SÃO PAULO

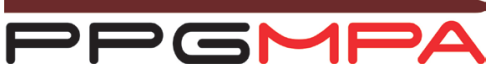

